7-19-2021

\title{
The Experience of OFF Periods in Parkinson's Disease: Descriptions, Triggers, and Alleviating Factors
}

\author{
Sneha Mantri \\ Madeline Lepore \\ Briana Edison \\ Margaret Daeschler \\ Catherine Kopil \\ Connie Marras \\ Lana Chahine
}

Follow this and additional works at: https://aah.org/jpcrr

Part of the Musculoskeletal Diseases Commons, Nervous System Diseases Commons, Neurology Commons, Neurosciences Commons, and the Other Pharmacy and Pharmaceutical Sciences Commons

\section{Recommended Citation}

Mantri S, Lepore M, Edison B, Daeschler M, Kopil CM, Marras C, Chahine LM. The experience of OFF periods in Parkinson's disease: descriptions, triggers, and alleviating factors. J Patient Cent Res Rev. 2021;8:232-8. doi: 10.17294/2330-0698.1836

Published quarterly by Midwest-based health system Advocate Aurora Health and indexed in PubMed Central, the Journal of Patient-Centered Research and Reviews (JPCRR) is an open access, peer-reviewed medical journal focused on disseminating scholarly works devoted to improving patient-centered care practices, health outcomes, and the patient experience. 


\title{
The Experience of OFF Periods in Parkinson's Disease: Descriptions, Triggers, and Alleviating Factors
}

\author{
Sneha Mantri, MD, MS, ${ }^{1}$ Madeline Lepore, BSN, ${ }^{2}$ Briana Edison, MPH, ${ }^{2}$ Margaret Daeschler, BA, ${ }^{3}$ \\ Catherine M. Kopil, PhD, ${ }^{3}$ Connie Marras, MD, PhD, ${ }^{4}$ Lana M. Chahine, MD ${ }^{2}$ \\ ${ }^{1}$ Department of Neurology, Duke University, Durham, NC; ${ }^{2}$ Department of Neurology, University of Pittsburgh, \\ Pittsburgh, PA; ${ }^{3}$ The Michael J. Fox Foundation for Parkinson's Research, New York, NY; ${ }^{4}$ Edmond J. Safra \\ Program in Parkinson's Disease, Toronto Western Hospital, University of Toronto, Toronto, Canada
}
Purpose
Wearing off of Parkinson's disease medication is common, but triggers and coping strategies for this transient phenomenon are poorly understood. We aimed to assess the lived experience of OFF periods for people with Parkinson's disease.
Methods Participants in the longitudinal Fox Insight study who endorsed OFF periods were invited to complete a survey consisting of both multiple-choice and free-text responses. Descriptive statistics were used to summarize multiple-choice responses, and free-text responses were classified into themes through iterative discussion by 3 movement disorders specialists.

Results A total of 2110 participants $(52.4 \%$ male $)$ completed the survey. Tremor was the most common description of OFF periods $(n=1038,49.2 \%)$, followed by gait changes $(n=535,25.4 \%)$ and rigidity $(n=430,20.4 \%)$. Of 1498 specific triggers for OFF symptoms, the most common was stress $(n=920$, $61.4 \%)$, followed by anxiety/depression $(n=476,31.8 \%)$ and tiredness/fatigue $(n=351,23.4 \%)$. Common coping strategies ( $n=1416$ responses) included exercise $(n=678,47.9 \%)$, taking a break $(n=504,35.6 \%)$, and meditation $(n=276,19.5 \%)$.

Conclusions Although OFF periods are common, the individual experiences of OFF vary. This knowledge could be used to develop new counseling strategies for OFF periods in people with Parkinson's disease. (J Patient Cent Res Rev. 2021;8:232-238.)

Keywords Parkinson's disease; wearing off; communication barriers; triggers; coping strategies

$\mathrm{W}$ ith progression of Parkinson's disease (PD), more than two-thirds of patients develop motor fluctuations, ${ }^{1}$ particularly OFF periods, during which medications wear off gradually or abruptly, resulting in the return of parkinsonian features. ${ }^{2}$ The severity and unpredictability of OFF time are major drivers of health-related quality of life among people with $\mathrm{PD} ;{ }^{3}$ thus, the recognition and management of OFF symptoms is critical. Despite therapeutic advances over the last half-century, OFF symptoms remain a potentially disabling feature of the illness, ${ }^{4}$ with patients relying on novel formulations of levodopa ${ }^{5}$ or turning to surgical strategies ${ }^{6}$ to address inadequate or unpredictable responses to medical therapy.

Corresponding author: Sneha Mantri, MD, MS, Duke Health Center, 932 Morreene Rd., Box 3333, Durham, NC 27705 (sneha.mantri@duke.edu)
While extensive clinical research has been done on OFF periods, the "lived experience" of OFF periods for people with PD (ie, how they experience OFF periods, communicate about them, and manage them) is not well understood. Classic OFF motor symptoms are frequently recognized by clinicians and can be tracked by questionnaires, ${ }^{7}$ yet OFF nonmotor symptoms are less commonly assessed, even though they may be more disabling to patients, ${ }^{8}$ and OFF episodes may go undetected by clinicians. Several factors may account for this, including perceived barriers to communication about OFF episodes. ${ }^{9}$ An investigation of the lexicon patients use to communicate about OFF periods, and how they describe their experience during OFF episodes, could improve detection of OFF episodes through physician education and the refinement of patient-reported outcomes to better reflect patient perceptions and description of their OFF symptoms.

Additionally, little is known about triggers and alleviating factors for OFF periods, aside from their temporal association with medication doses. A better 
understanding of OFF triggers and the strategies patients use to treat symptoms or lessen their severity could help identify nonpharmacological strategies to manage these OFF periods in PD.

The objective of this study was to elucidate the ways people with PD describe their OFF periods, including triggers and coping strategies.

\section{METHODS}

The study design has previously been described in detail. ${ }^{8}$ Briefly, participants were recruited from the Fox Insight study, ${ }^{10}$ an online-only cohort study of individuals 18 years of age and older with self-reported PD versus healthy controls. Demographic information for the present analysis, including age, education level, disease duration of $\mathrm{PD}$, and specialty of the clinician who diagnosed PD, were collected on all participants as part of the Fox Insight study.

On November 26, 2018, a questionnaire was deployed via email to a subset of the Fox Insight cohort who had selfreported PD, reported taking 1 or more PD medications, and were living in the United States. Those who clicked on the email were taken to the following screening question: Many individuals with Parkinson's disease fluctuate between periods in which their symptoms are better controlled and periods during which symptoms return. We refer to the periods during which symptoms are better controlled as $O N$, and periods during which symptoms return as OFF. Based on this definition of OFF, do you experience OFF periods?

Those responding "no" were excluded from participation in this survey study; those responding "yes" received a series of free-text and multiple-choice questions assessing their experiences of fluctuations and OFF periods. The online survey was open for 4 weeks, and subjects could return to the questionnaire as many times as needed over that time to complete responses. Survey assessments analyzed included:

1. When you talk with your family and friends, what do you call the periods where your PD symptoms return? [multiple-choice: OFF periods, OFF episodes, OFF time, something else (please specify, free text, unlimited characters)].

2. In the space provided below please describe your experience when you are OFF [free text, unlimited characters].

3. Are there triggers, such as anxiety or stress, which can bring on an OFF period for you? [yes/no] (if yes): What are those triggers? [free text, unlimited characters].

4. Other than taking medication, is there anything you do during your OFF periods to help manage your
PD symptoms? [yes/no] (if yes): Other than taking medication, what do you do during your OFF periods to help manage your PD symptoms? [free text, unlimited characters].

Inclusion criteria for this study were the availability of data on age, sex, and endorsed OFF periods and a response provided to at least 1 of the 4 aforedescribed assessments. Exclusion criteria were absence of a selfreported PD diagnosis at any Fox Insight visits up to the time of survey, missing participant age, or implausible age of PD onset.

Descriptive statistics were used to summarize demographics and proportion responding to each answer on multiple-choice questions. Free-text responses were reviewed by authors M.L. and B.E. and grouped into categories or themes, which were reviewed and refined through iterative classification by movement disorders specialists (S.M., L.M.C.). Responses could be classified into multiple categories if appropriate. If a response was not provided on a given question, that item was considered missing for that subject.

\section{RESULTS}

Of the 13,359 eligible and invited Fox Insight participants, 2684 started the survey (20\% response rate). Of these, 507 surveys were terminated when respondents reported no OFF periods and an additional 49 did not answer any questions in the survey. Of the remaining 2128, 15 had inconsistency in self-reported diagnosis across Fox Insight study visits, 6 had missing age at survey, and 3 reported their year of birth as the year of PD onset. Thus, the final sample for this analysis was 2110 respondents.

Mean age of respondents was 66.6 (standard deviation [SD]: 8.5) years, 52.4\% were male, 1157 (58.6\%) had 13-16 years of education, and 655 (33.2\%) had more than 16 years of education (Table 1). Mean disease duration at the time of survey was 6.1 (SD: 5.1) years. Mean duration of OFF time was 3.5 (SD: 2.9) hours, and OFF time accounted for a mean of $22.3 \%$ (SD: $20.2 \%$ ) of awake hours. Hours of OFF time was missing for 21 respondents. The most commonly used medication was carbidopa-levodopa ( $\mathrm{n}=1900,90.1 \%) ; 354$ (16.8\%) respondents reported use of amantadine.

There were 2101 responses to the question "When you talk with your family and friends, what do you call the periods where your PD symptoms return?" Of these, 122 (5.8\%) selected "OFF episodes," 767 (36.5\%) "OFF periods," 497 (23.7\%) "OFF time," and 715 (34.0\%) "something else." For those who indicated something else, 455 specified a free-text response (Table 2). The most common category 
Table 1. Sample Characteristics $(\mathrm{N}=2110)$

\begin{tabular}{lc}
\hline Characteristic & $\mathbf{n}(\%)$ or \\
mean (SD)
\end{tabular}

$N / A$, not applicable; $S D$, standard deviation.

of free-text response was medication-related (examples: need meds, end of meds, feels like I forgot to take meds), which was referenced by 78 respondents (17.1\%). Specific symptoms were referenced by 99 respondents (21.8\%), with motor symptoms (shaking, stiffness, drooping) comprising 76 responses, nonmotor symptoms (brain-dead, fuzzy) comprising 14 responses, and gait symptoms (frozen, stuck, legs do not work) comprising 9 responses. Also, 86 respondents (18.9\%) reported that they did not discuss their OFF periods with others or do not have specific language to describe OFF periods.

There were 2110 responses to the question asking participants to describe their experience when they are in an OFF state (Online Supplemental Table S1). Of these, 1926 (91.3\%) described specific symptoms, with tremor (49.2\%), gait and freezing problems $(25.4 \%)$, and rigidity (20.4\%) being most common motor symptoms and fatigue (18.8\%), mood/anxiety (15.1\%), and cognitive symptoms $(15.5 \%)$ being the most common nonmotor symptoms. Additionally, 356 (16.9\%) referenced the phenomenon of motor fluctuations, mentioning either time of day or timing of medication.

Of the 2097 who provided a response regarding triggers of OFF periods, $1568(74.8 \%)$ reported triggers for their OFF periods. Specific triggers were described by 1498 (71.4\%) respondents, which are summarized in Table 3. The most commonly reported trigger was stress $(n=920$, $61.4 \%)$, followed by anxiety/depression $(n=476,31.8 \%)$ and tiredness/fatigue $(\mathrm{n}=351,23.4 \%)$. Medication timing was noted as a trigger by only $31(2.1 \%)$ respondents.

In regard to coping strategies, of 2106 respondents, 1447 indicated they have strategies to manage OFF periods other than taking medication and 1416 (67.2\%) described these strategies (as detailed in Table 3). The most common coping strategy was exercise $(n=678$, $47.9 \%)$, followed by taking a break $(\mathrm{n}=504,35.6 \%)$ and meditation $(\mathrm{n}=276,19.5 \%)$.

\section{DISCUSSION}

People with PD described a variety of symptoms and triggers of OFF periods as well as many coping strategies to help deal with and palliate the symptoms of these OFF periods. Survey respondents reported spending nearly a quarter of their waking hours in the OFF state, which comprised both motor and nonmotor features. Tremor, rigidity, and gait problems were commonly reported motor symptoms, which is consistent with other work on bothersome aspects of OFF periods. ${ }^{8}$ As for nonmotor symptoms, pain and other sensory symptoms were mentioned by $24.9 \%$ of patients. The mechanism underlying this association is poorly understood - pain in PD does not always correlate with motor symptoms ${ }^{11}$ - although pain is a significant factor in poor quality of life among people with PD. Overall, our results are consistent with prior studies that suggested OFF periods are multifaceted $^{2}$ and that careful communication is needed to elucidate exactly which symptoms are most bothersome to patients. ${ }^{8,9}$

In our study, $26.9 \%$ of respondents explicitly connected their OFF symptoms with medications when discussing their experience with others, and $16.9 \%$ referenced motor fluctuations when describing their OFF symptoms. Importantly, commonly named triggers included stress, anxiety, and other mood symptoms. The majority of patients identified coping strategies that do not involve the use of medications, such as exercise, meditation, or removing themselves from a stressful situation. When drugs or supplements were mentioned, 
Table 2. Free-Text Descriptors of Terminology Used by Respondents $(n=455)$ to Describe OFF Periods

\begin{tabular}{|c|c|c|}
\hline Category & Sample text & n (\%) \\
\hline $\begin{array}{l}\text { Medication-related, } \\
\text { nonspecific }\end{array}$ & $\begin{array}{l}\text { I usually just say that I need to take my medication, need meds, end of meds, } \\
\text { feels like I forgot to take meds }\end{array}$ & $78(17.1)$ \\
\hline $\begin{array}{l}\text { Symptom-based, } \\
\text { motor }\end{array}$ & $\begin{array}{l}\text { just say that my arm is shaking, symptomatic, twitchy, dyskinesia, drooping, } \\
\text { stiffness, shaky, weak, spastic, have the shakes, have to move }\end{array}$ & $76(16.7)$ \\
\hline Don't discuss it & $\begin{array}{l}\text { don't say anything, don't talk to them, don't talk to others about it, don't speak } \\
\text { of them very often, don't talk to family or friends, never really discussed it, I } \\
\text { don't mention them }\end{array}$ & $59(13.0)$ \\
\hline OFF & just off, having an off day, feeling off, different, out of tune & $44(9.7)$ \\
\hline $\begin{array}{l}\text { Medication-related, } \\
\text { OFF-specific }\end{array}$ & my meds are off, my meds wore off, medicine wearing off & $42(9.2)$ \\
\hline General unwell & $\begin{array}{l}\text { don't feel good at all, crashing, feel bad, feeling bad, not doing well, not feeling } \\
\text { well, having trouble }\end{array}$ & $29(6.4)$ \\
\hline Bad days & bad day, bad days, good days and bad days, hard day, tough day & $28(6.2)$ \\
\hline $\begin{array}{l}\text { No specific name, } \\
\text { don't think about it }\end{array}$ & don't call it anything, don't have a name, hadn't given it a name, nothing & $27(5.9)$ \\
\hline $\begin{array}{l}\text { Heightened sense of } \\
\text { Parkinson's }\end{array}$ & Parkinson's symptoms, being parkinsony [sic], god damn parkinsons [sic] & $23(5.1)$ \\
\hline $\begin{array}{l}\text { No specific name, but } \\
\text { feel it is recognized }\end{array}$ & $\begin{array}{l}\text { I don't really have a name for it, we all just know what is going on, active, don't } \\
\text { use a consistent descriptor }\end{array}$ & $17(3.7)$ \\
\hline Down time & down time, low time & $14(3.1)$ \\
\hline $\begin{array}{l}\text { Symptom-based, } \\
\text { cognitive }\end{array}$ & inability, worthless, brain dead, tired, fuzzy & $14(3.1)$ \\
\hline Frozen & gait freeze, frozen, legs do not work, slow motion mode, slow motion, stuck & $9(2.0)$ \\
\hline Bad time & bad time, bad times, good times and not so good times & $8(1.8)$ \\
\hline Rough time & rough times, having a rough time, tough time & $5(1.1)$ \\
\hline Funk & being funky, in a funk & $4(0.9)$ \\
\hline Breakthrough & breakthrough, break thru [sic] & $3(0.7)$ \\
\hline Flare & flare-ups, acting up & $3(0.7)$ \\
\hline "It's back" & they're back, its [sic] back & $2(0.4)$ \\
\hline Other & $\begin{array}{l}\text { tide is out, got me, adjustments, morning blahs, I told my doctor but he didn't } \\
\text { seem to think it was significant, guests, transitions, I'm in a tunnel, not online, } \\
\text { wiped out, being pokey, I feel stuff }\end{array}$ & $15(3.3)$ \\
\hline
\end{tabular}

these consisted most commonly of cannabinoids; anxiolytics, pain medications or supplements, were less common. The reliance on non-levodopa-based strategies for coping with OFF periods likely reflects the nonmotor characteristics of OFF periods for people with PD and identifies possible areas for future therapeutic development.

By contrast, most literature for clinicians on the management of OFF periods focuses on the pharmacodynamics and pharmacokinetics of levodopa in advanced PD. ${ }^{2,46}$ This highlights a potential unmet need to develop treatment strategies that address nonmotor triggers of OFF periods, beyond novel formulations of levodopa. In particular, the most commonly reported coping strategy for OFF symptoms was exercise. This is consistent with other work $^{12,13}$ that promotes the importance of exercise for people with PD. Nevertheless, lack of clinician discussion about exercise is commonly reported by patients as a barrier to physical activity. ${ }^{14-17}$ More counseling of patients around exercise, meditation, or other stress-management techniques may be helpful in reassuring patients and their families that there are effective nonpharmacological and nonsurgical strategies to manage OFF periods.

Interestingly, although all respondents agreed that they experienced OFF periods as a precondition of receiving the survey, 1 in 4 reported that they had either not discussed OFF periods with others or that they had no specific language for doing so. Better ascertainment strategies, perhaps enhanced by wearable sensor data, ${ }^{18,19}$ are needed to ensure clinicians are aware of OFF periods when present in their patients. 
Table 3. Free-Text Triggers $(n=1498)$ and Coping Strategies (1416) for OFF Periods

\begin{tabular}{|c|c|c|c|}
\hline Triggers & Sample text & $\mathbf{n}$ & $\%$ of 1498 \\
\hline Stress & Any stress is the biggest thing that throws me off & 920 & 61.4 \\
\hline Anxiety or depression & Anxiety, when I get worried about things & 476 & 31.8 \\
\hline Tiredness/fatigue & Too little sleep, fatigue is biggest trigger & 351 & 23.4 \\
\hline Social situations & Having dinner out with friends, crowds, unexpected visitors & 118 & 7.9 \\
\hline Cold or heat exposure & Cold weather & 102 & 6.8 \\
\hline Family issues & My son, having an argument with a loved one, mother-in-law, family drama & 96 & 6.4 \\
\hline Anger & Confrontations & 71 & 4.7 \\
\hline Food intake & Hunger, food delay, irregular meals & 57 & 3.8 \\
\hline Medication-related & Trying to get something done before Med time & 31 & 2.1 \\
\hline Driving & Driving in traffic & 16 & 1.1 \\
\hline Other, miscellaneous & $\begin{array}{l}\text { Loud noises, too much noise, airports, airline travel, alcohol, time of day } \\
\text { (more off in the evenings) }\end{array}$ & 92 & 12.3 \\
\hline Coping strategies & Sample text & $\mathbf{n}$ & $\%$ of 1416 \\
\hline Exercise & $\begin{array}{l}\text { Stretching, walking, yoga, cycling, biking, hiking, keep moving, staying active, } \\
\text { physical therapy exercises, vigorous exercise, lifting weights, LSVT exercises }\end{array}$ & 678 & 47.9 \\
\hline Take a break/relax & $\begin{array}{l}\text { Calm myself, try to relax, remove myself from the situation, rest quietly, } \\
\text { rest, sit down, lie very still with my eyes closed, get away from everyone, } \\
\text { quiet time, just ignore it, slow down, avoid stress }\end{array}$ & 504 & 35.6 \\
\hline $\begin{array}{l}\text { Mindfulness/positive } \\
\text { thinking/breathe/ } \\
\text { massage }\end{array}$ & $\begin{array}{l}\text { Respiratory, deep breaths, breathing exercises, tell myself to have good } \\
\text { posture, talk out loud to myself, concentrating on relieving the tightness, } \\
\text { massage, relaxation exercises, try to stay calm and be as positive as possible, } \\
\text { tai chi, mindfulness, focus on breathing, mental simulation, hold my hands } \\
\text { folded and calming myself, mindfulness music, eliminate stress, qigong }\end{array}$ & 276 & 19.5 \\
\hline Sleep/nap & $\begin{array}{l}\text { Take a nap, force myself to sleep, bed rest, lay down in bed, rest or sleep } \\
\text { sometimes charges me back up }\end{array}$ & 256 & 18.1 \\
\hline Drink/eat & $\begin{array}{l}\text { Hydration, water, diet program designed for people with Parkinson's, suck } \\
\text { on a piece of candy, eating, martinis, alcoholic drink, tea, carbonated } \\
\text { beverages, citrus, protein }\end{array}$ & 97 & 6.9 \\
\hline Activity & $\begin{array}{l}\text { Crosswords, puzzles, word searches, gardening, making art, genealogy } \\
\text { project, cleaning, stay occupied with activity, focus on some work, } \\
\text { counting, puzzles, tasks, chores, singing }\end{array}$ & 94 & 6.6 \\
\hline Read & Reading for pleasure, reading a book & 61 & 4.3 \\
\hline Technology & $\begin{array}{l}\text { I play on my computer, listen to audiotape, surf internet, listen to online } \\
\text { stories, television, use phone, funny movies }\end{array}$ & 58 & 4.1 \\
\hline Music & Soothing music, listen to online music, mindfulness music & 52 & 3.7 \\
\hline Heat & $\begin{array}{l}\text { Heating pad, hot bath, hot tub, get warm if I'm cold, heat therapy, sauna, } \\
\text { shower }\end{array}$ & 49 & 3.5 \\
\hline CBD/cannabis & CBD oil, vape cannabis, CBD gummies, marijuana, THC & 48 & 3.4 \\
\hline Social & Being engaged socially with others, socializing, conversation, talk with friends & 28 & 2.0 \\
\hline Focus on movements & $\begin{array}{l}\text { Deliberate movement to oppose dystonia, flexion, extension, holding } \\
\text { hands in certain positions, focus on not falling while walking }\end{array}$ & 26 & 1.8 \\
\hline Anti-anxiety medication & Klonopin, Xanax, valium & 19 & 1.3 \\
\hline Animals & Walk the dog, go to the barn, hold my cats & 15 & 1.1 \\
\hline Pray & --- & 15 & 1.1 \\
\hline Pain medications & Advil, gabapentin, Bengay, ibuprofen, Tylenol & 10 & 0.7 \\
\hline Supplements & Essential oils, $B_{12}$, dopatone, glutathione, mucuna, quinine, fish oil, coconut oil & 6 & 0.4 \\
\hline Deep brain stimulation & --- & 5 & 0.4 \\
\hline Other & $\begin{array}{l}\text { Change, use red pointer to lead the way, keeping, vibrating chair/pads } \\
\text { for tremors, ice pack, avoid driving, sex, acupuncture, rework lifestyle, } \\
\text { quick release pills, gas x, foam roller, hold a baby, extra dose of Sinemet, } \\
\text { intellectual willpower, compression device, laxative, cognitive behavior } \\
\text { therapy, bowel movement, cry, swear }\end{array}$ & 67 & 4.7 \\
\hline
\end{tabular}




\section{Strengths and Limitations}

To our knowledge, this is the first large-scale study of the experience of OFF periods in people with PD and builds on prior qualitative work examining the OFF experience. ${ }^{4,8}$ Because OFF symptoms are strongly associated with health-related quality of life among people with $\mathrm{PD},{ }^{3}$ this study provides a glimpse into understanding this common and critical aspect of the disease. Noted strengths of the current study include a large cohort that comprised nearly $50 \%$ women, a group otherwise underrepresented in PD research. Additionally, few prior studies examine the impact and experience of OFF periods from the patient's perspective; ${ }^{20}$ this questionnaire was built directly on interviews with patients $^{21}$ and thus captures a range of lived experience reported by patients rather than assumed by clinicians.

Nevertheless, some important study limitations should be acknowledged. First, the self-reported nature of Fox Insight makes the validity of a PD diagnosis somewhat uncertain; however, we note that nearly all reported that they had been diagnosed by a neurologist or movement disorders specialist, suggesting a relatively good confidence in the validity of the diagnosis, and the pattern of responses from the online Fox Insight cohort is similar to well-defined PD cohorts assessed in person. ${ }^{22}$ Specifically for this study, individuals without PD would not experience OFF periods and thus would have been screened out before starting the survey. Second, we were unable to independently assess or confirm the wearing off symptoms reported by participants. However, the congruent responses to questions about the experience of OFF periods and the consistency with reports from other surveys about OFF periods provides face validity to the self-report in this analysis. Finally, this cohort consisted mainly of highly educated English-speaking Caucasians living in the United States; thus, our findings may not be generalizable to other PD subpopulations.

\section{CONCLUSIONS}

This study adds important knowledge about the way people with Parkinson's disease experience OFF periods and how patients cope with these symptoms. Although participants described their OFF symptoms, triggers, and coping strategies in detail, a substantial proportion had not previously discussed this important aspect of illness experience with others. OFF symptoms described by participants included both motor (tremor, gait, rigidity) and nonmotor (pain, fatigue, mood, cognitive) domains, while common coping strategies included exercise, taking a break, and mindfulness meditation.

The development of comprehensive counseling strategies for patients and care partners centered around OFF communication, encompassing both preventing OFF and coping with the OFF periods that do occur, is an unmet need among people with PD. Such work could better inform patient and family counseling on the recognition and management of OFF periods with respect to taking medication for PD.

\section{Patient-Friendly Recap \\ - Patients receiving treatment for Parkinson's disease commonly experience "OFF" periods during which their medications lose effectiveness and their symptoms re-emerge. \\ - The authors surveyed more than 2000 people with Parkinson's and a history of OFF periods. \\ - The most frequently self-reported triggers of OFF were stress, anxiety/depression, and tiredness. Returning symptoms included tremor, changes in gait, and rigidity. Exercise and meditation were two common coping strategies. \\ - Patients who are prescribed Parkinson's medication should be counseled on ways to manage potential OFF periods.}

\section{Acknowledgments}

We would like to thank the Parkinson's community for participating in this study to make this research possible.

\section{Author Contributions}

Study design: Kopil, Marras, Chahine. Data acquisition or analysis: Mantri, Lepore, Edison, Daeschler, Chahine. Manuscript drafting: Mantri. Critical revision: Lepore, Edison, Daeschler, Kopil, Marras, Chahine.

\section{Conflicts of Interest}

Sneha Mantri receives research support from The Michael J. Fox Foundation (MJFF), the Parkinson Foundation, and Cerevel Therapeutics, was a paid consultant to MJFF, is a study site investigator for a study sponsored by Neuraly Rho, is a study site subinvestigator for a study sponsored by Biogen, and is contracted with Deep Brain Innovations, LLC, and Grey Matter Technologies, Inc. Margaret Daeschler was an employee of the sponsor, MJFF, at the time this work was done. Catherine Kopil is an employee of MJFF. Connie Marras was a paid consultant for Acorda Therapeutics, is on the advisory board of Denali Therapeutics, received honoraria for teaching from EMD Serono, and is a steering committee member for MJFF Grants Canadian Institutes of Health Research, the Parkinson's Foundation, the National Institutes of Health, and the International Parkinson and Movement Disorders Society, and is contracted with Grey Matter Technologies. Lana Chahine receives research support from MJFF, has received travel payment from MJFF to MJFF conferences, is a paid consultant to MJFF, receives research support from the University of Pittsburgh Medical Center Competitive Medical Research Fund, is study site investigator for a study sponsored by 
Biogen, is a site subinvestigator for a study sponsored by Voyager, received payment from Elsevier (for book authorship), and receives royalties from Wolters Kluwer (for book authorship).

\section{Funding Sources}

This work occurred as part of The Michael J. Fox Foundation's Parkinson's Disease Education Consortium 2018 (PDEC 2018) project. The PDEC is sponsored by the following industry partners: ACADIA Pharmaceuticals, Adamas Pharmaceuticals, Intec Pharma, Lundbeck Inc., and Sunovion Pharmaceutical. The Fox Insight study is funded by The Michael J. Fox Foundation for Parkinson's Research.

\section{References}

1. Ahlskog JE, Muenter MD. Frequency of levodopa-related dyskinesias and motor fluctuations as estimated from the cumulative literature. Mov Disord. 2001;16:448-58. CrossRef

2. Chou KL, Stacy M, Simuni T, et al. The spectrum of "off" in Parkinson's disease: What have we learned over 40 years? Parkinsonism Relat Disord. 2018;51:9-16. CrossRef

3. Kerr C, Lloyd EJ, Kosmas CE, et al. Health-related quality of life in Parkinson's: impact of 'off' time and stated treatment preferences. Qual Life Res. 2016;25:1505-15. CrossRef

4. Rastgardani T, Armstrong MJ, Gagliardi AR, Grabovsky A, Marras C. Experience and impact of OFF periods in Parkinson's disease: a survey of physicians, patients, and carepartners. J Parkinsons Dis. 2020;10:315-24. CrossRef

5. Aradi SD, Hauser RA. Medical management and prevention of motor complications in Parkinson's disease. Neurotherapeutics. 2020;17:1339-65. CrossRef

6. Antonini A, Moro E, Godeiro C, Reichmann H. Medical and surgical management of advanced Parkinson's disease. Mov Disord. 2018;33:900-8. $\underline{\text { CrossRef }}$

7. Antonini A, Martinez-Martin P, Chaudhuri RK, et al. Wearing-off scales in Parkinson's disease: critique and recommendations. Mov Disord. 2011;26:2169-75. CrossRef

8. Chahine LM, Edison B, Daeschler M, et al. The most bothersome aspects of off periods reported by individuals with Parkinson's disease. Mov Disord Clin Pract. 2020;7:284-92. CrossRef

9. Armstrong MJ, Rastgardani T, Gagliardi AR, Marras C. Barriers and facilitators of communication about off periods in Parkinson's disease: qualitative analysis of patient, carepartner, and physician interviews. PLoS One. 2019;14(4):e0215384. CrossRef
10. Smolensky L, Amondikar N, Crawford K, et al. Fox Insight collects online, longitudinal patient-reported outcomes and genetic data on Parkinson's disease. Sci Data. 2020;7(1):67. CrossRef

11. Cury RG, Galhardoni R, Fonoff ET, et al. Sensory abnormalities and pain in Parkinson disease and its modulation by treatment of motor symptoms. Eur J Pain. 2016;20:151-65. CrossRef

12. Rafferty MR, Schmidt PN, Luo ST, et al. Regular exercise, quality of life, and mobility in Parkinson's disease: a longitudinal analysis of National Parkinson Foundation Quality Improvement Initiative data. J Parkinsons Dis. 2017;7:193-202. CrossRef

13. Lin I, Edison B, Mantri S, et al. Triggers and alleviating factors for fatigue in Parkinson's disease. PLoS One. 2021;16(2):e0245285. CrossRef

14. Afshari M, Yang A, Bega D. Motivators and barriers to exercise in Parkinson's disease. J Parkinsons Dis. 2017;7:703-11. CrossRef

15. Khalil H, Nazzal M, Al-Sheyab N. Parkinson's disease in Jordan: barriers and motivators to exercise. Physiother Theory Pract. 2016;32:509-19. CrossRef

16. Ellis T, Boudreau JK, DeAngelis TR, et al. Barriers to exercise in people with Parkinson disease. Phys Ther. 2013;93:628-36. CrossRef

17. Schootemeijer S, van der Kolk NM, Ellis T, et al. Barriers and motivators to engage in exercise for persons with Parkinson's disease. J Parkinsons Dis. 2020;10:1293-9. CrossRef

18. Aich S, Youn J, Chakraborty S, et al. A supervised machine learning approach to detect the on/off state in Parkinson's disease using wearable based gait signals. Diagnostics (Basel). 2020;10(6):421. CrossRef

19. Farzanehfar P, Woodrow H, Horne M. Assessment of Wearing Off in Parkinson's disease using objective measurement. J Neurol. 2021;268:914-22. CrossRef

20. Rastgardani T, Armstrong MJ, Gagliardi AR, Marras C. Understanding, impact, and communication of "Off" periods in Parkinson's disease: a scoping review. Mov Disord Clin Pract. 2018;5:461-70. CrossRef

21. Chahine L, Marras C, Daeschler M, et al. Exploring the experience of wearing off in Parkinson's disease: a qualitative research approach. (abstr.) Neurology. 2019;92(15 Suppl):P5.8-050.

22. Chahine LM, Chin I, Caspell-Garcia C, et al. Comparison of an online-only Parkinson's disease research cohort to cohorts assessed in person. J Parkinsons Dis. 2020;10:677-91. CrossRef

(C) 2021 Advocate Aurora Health, Inc. 